\title{
The Rebranding Path of LI-NING
}

\author{
Ziyan Duan ${ }^{1, \dagger}$, Xuhan $\mathrm{Lu}^{2, \dagger}$, Luchen Wang ${ }^{3,{ }^{*}, \dagger}$ \\ ${ }^{1}$ School of Accountancy, Shanghai University of Finance and Economics, Shanghai, 200433, China \\ ${ }^{2}$ Xingzhi College, Zhejiang Normal University, Hangzhou, 310000, China \\ ${ }^{3}$ School of Economics and Management, Tianjin Chengjian University, Tianjin, 300384, China \\ *Corresponding author.Email: duanziyan032@163.com; luxuhan@163.com; guanghua.ren@gecacademy.cn; \\ These authors contributed equally.
}

\begin{abstract}
LI-NING is a Chinese local sports brand obtaining increasing popularity in the past decade. However, the customers have also been critiqued due to its outdated product design and insufficiency of core technology, impeding further expansion in domestic and international markets. In this context, this paper attempts to discuss the rebranding path of LI-NING. As a result of our analysis, it is found that Li-Ning has focused too much on the promotion of fashion products while significantly ignoring its sports series and sports technology research and development. In this situation, it is suggested that LI-NING should better position its brand by improving its product standards and technologies, paying more attention to younger generation customer groups, and increasing its products publicity.
\end{abstract}

Keywords: Strategic management, Branding, and marketing, Rebranding, LI-NING

\section{INTRODUCTION}

LI-NING was founded in 1990 by Li Ning, who is one of the greatest gymnasts in China. The headquarter of LI-NING is situated in Beijing Zhongguancun Park, which is also known as the Chinese Silicon Valley. As can be seen in Figure 1, the Logo of LI-NING is made up of the first character of the founder's name (LI's L and NING's N). As for its designing style, the logo is conceptualized by the Chinese character "人 (human)" with the red color, standing for the sport spirits to be more powerful, stronger, more enthusiastic. This design is also consistent with the mission statement of LINING that is "sport burns passion" [1].

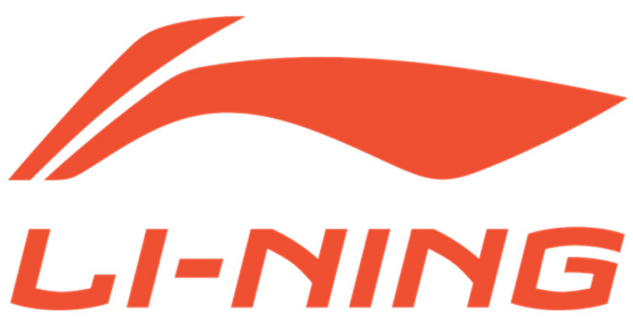

Figure 1 Brand logo of LI-NING

The products of LI-NING include a series of shoes, clothing, sports equipment, and accessories. It has also collaborated with numerous sports celebrities as its spokesperson. For instance, DeWayne Wade series basketball shoes are especially popular among the younger generation in China.

LI-NING's major target market is China, accounting for 98.5 percent of its total revenue [2]. Among all LINING's products, the best-seller is LI-NING sports clothing, taking up around 50 percent of its total sales [2]. Nevertheless, with respect to its international market, despite some improvements in financial performance these years, LI-NING has not gained as equal competitiveness as in China [2]. Thus, it can be said that there is still a long way to go for LI-NING to realize its internalization vision.

In the domestic market, LI-NING also encounters increasingly fierce market competition. Some of its major competitors are world-famous sports brands like "Nike" and "Adidas". Besides competing with international brands, LI-NING faces competitive pressure from domestic sports brands such as ANTA, XTEP, and $361^{\circ}$. For example, in the year 2020, Anta's sales exceeded LI-NING, which puts great pressure on Li Ning in the domestic market [3].

Based on the above introduction, it can be seen that, while LI-NING is making great progress, it also confronts massive competition, showing the need for LINING to optimize its competitive strategies. This report, thereby, would focus on the case of LI-NING and sets out to apply branding and marketing theories to 
investigate how LI-NING can obtain more competitive advantages through re-branding practices. The next section reviews some problems that need to be tackled in this study.

\section{PROBLEMS ANALYSIS FOR LI-NING}

This section reveals major challenges for LI-NING that have been uncovered in previous studies. In general, it has revealed that its sports series are of great weaknesses compared with its fashion series [3]. The first aspect is concerning the product design of Li-NING [3]. Previously, LI-NING's target market was post-80s. As its old-fashioned design cannot meet the emergent market needs, in 2015, LI-NING decided to dramatically reposition its target market and re-construct its brand image to attract millennials [3].

The re-branding efforts paid off since LI-NING's fashion series has gone viral after the 2018 Paris Fashion Week, and the brand gradually came into customers' sight as a stylish and trendy image [4]. The design combined various Chinese elements, including the silk road, Dunhuang folk stories, and some Chinese character designs [4]. The series of fashion clothing obtained great success in the Chinese market.

Nevertheless, its sportswear series left inadequate attention. Especially, young customers, who generally emphasize the appearance of their sports outfits, have an ineradicable impression of LI-NING sports products and regard them as outdated [5]. Meanwhile, LI-NING's impact on generation Z's sportswear, which is their current audience, is not as significant as before [5]. As a result, LI-NING has to fill the gap by optimizing the product design for its sports series.

More than the design, the sports series of LI-NING's products lack core technology compared to its competitors [5]. Apart from the technology called "LINING GONG," a special design on shoe soles that can improve sports performance, there are few technological elements on other professional products. In comparison, according to its competitors' annual report, Nike has the most research and development input, followed by Adidas and ANTA [5]. Hence, it can be seen that LINING performed inferior compared to its competitors in the research and development dimension. As LI-NING has clearly manifested on its official website that it is a sports-oriented brand, it is believed that the technological improvement of its sportswear and sports equipment is of high importance to the company.

Finally, LI-NING has put much effort into promoting the fashion series, including inviting celebrities for sponsorship, constantly being on Paris Fashion Week, and actively twittering on social media [6]. However, it neglects the marketing for the sportswear series. Among all its sports products, advertisements and promotional campaign for them are extremely rare [6].

In sum, it can be argued that the strategic positioning of LI-NING'S sports series is problematic. Therefore, this report would then conduct some analysis to help LINING re-design its sports series branding and marketing strategy.

\section{SITUATIONAL ANALYSIS FOR LI-NING}

Table 1. Environmental analysis

\begin{tabular}{|c|c|}
\hline $\begin{array}{l}\text { Strengths } \\
\text { - Strong market power } \\
\text { - High Market credence } \\
\text { - Famous native brand } \\
\text { - Affluent public resources } \\
\text { - High brand recognition } \\
\text { - Ample financial basis }\end{array}$ & \begin{tabular}{ll} 
& \multicolumn{1}{c}{ Weaknesses } \\
- & Inadequate marketing \\
campaigns \\
- & Unclear brand image \\
- & Lack of technology \\
input \\
$-\quad \begin{array}{l}\text { Lack of outstanding } \\
\text { design }\end{array}$
\end{tabular} \\
\hline $\begin{array}{l}\text { Opportunities } \\
\text { - The patriotic trend } \\
\text { - Enlarged Sales Channels } \\
\text { - Governmental policy } \\
\text { support } \\
\text { - Improved Technology of } \\
\text { the manufacturing } \\
\text { industry }\end{array}$ & $\begin{array}{l}\text { Threats } \\
\text { - Fierce competition in the } \\
\text { sportswear industry } \\
\text { - Customers' preference of } \\
\text { international sport brands }\end{array}$ \\
\hline
\end{tabular}

A situational analysis based on the SWOT model was performed in this section, and the results are shown in Table 1. Since the World Olympic Champion founds it, Mr. Li Ning, who has sponsored the development of Chinese sports for many years, LI-NING has now become a representative of the Chinese sports industry [7]. Thus, it can be said that LI-NING has already won a great level of fame in China as a native brand. Also, as many products of LI-NING involve Chinese elements, a lot of people supporting the native brand in China will be attracted by this brand. In addition, LI-NING has gained wide public resources, brand credit, and high brand recognition. For instance, LI-NING has abundant funds, and the revenue of the Group grew by $4.2 \%$ in 2020 , and the net profit margin rose from $9.1 \%$ to $11.7 \%$ [7]. Despite its high profitability, the prices of LI-NING products are reasonable, and most people can afford them [7].

Concerning the weaknesses of LI-NING, its promotion is not well-performed. For example, the brand repeatedly changes its slogan over the past years. Plus, its concentration perceived by the public is fashion apparel, while LI-NING still defines itself as a sportsfocused brand [6]. The information conveyed to customers makes the brand image confusing. The style and the technology features of LI-NING also need to 
improve, and its brand personality is much weaker than those international brands such as NIKE or Adidas [7].

With respect to the opportunities, the foremost one is that people can buy anything online in China, making it more convenient for potential customers to reach LINING products [5]. The policy of "Made in China 2025" also provides supports for the improvement of manufacturing technology. Moreover, the Chinese domestic political and social-cultural environments would have positive impacts on local brands. For example, the Xinjiang cotton event in March 2021 brought on a considerable number of Chinese consumers to turn back to domestic brands. This may be an excellent opportunity for LI-NING to take advantage of patriotism.

Finally, concerning the external threats, it is clear that LI-NING is experiencing immense marketing competition because many Chinese customers still prefer to buy international brands like NIKE or those cheaper Chinese brands like ANTA [3]. Also, while LINING aims to become a renowned fashionable worldleading professional sports brand, the brand's performance can still not fully meet its aspiration, especially in terms of the professional sports series. Nike and Adidas are still two main brands that take up a huge market share, and customers tend to trust more on their quality and design [8].

\section{AUDIENCE AND TREND ANALYSIS FOR LI-NING}

LI-NING's target customers can be categorized into two personas, audiences of its fashion series and sportswear. Since LI-NING's fashion collections have been largely improved on its design, its target audiences believe that LI-NING is becoming more and more trendy and more suitable for their aesthetic tastes. Also, previous studies found that LI-NING's customers are mainly from the first and second-tier cities, which indicates that they have more options between numerous brands and hold higher product standards [4]. A point worth to be mentioned is that LI-NING's target customers are young people under 30, and most of them are still full-time students whose income is below 5000RMB a month; thereby, they may not have strong purchase powers [5].

As for the sports series, extant studies found that LINING's apparel design is comparatively outdated [8]. Besides the design, sportswear aims at those who have exercise requirements and expect high comfort level and function. Apart from the technology input on running shoes, LI-NING has little competence in other products compared with similar quality products from other brands, which may even be cheaper than LI-NING. It has also been mentioned that LI-NING has serious homogeneity with other domestic sports brands and has no highlights compared with foreign sports brands [7]. As a result, it would take a long way for LI-NING's sports series to catch up.

As for the trend analysis, the sports apparel industry shows a booming trend in recent years. The sales of sportswear increase constantly and reached 237.83 billion RMB in 2018, and the number of people regularly participating in exercise ascends as well [7]. Plus, since the outbreak of Covid-19 in 2020, people are becoming increasingly concerned about personal health issues. The overall trend of the whole industry is prosperous; therefore, LI-NING has a chance to gain a greater return if it can better design its branding and marketing strategies. Based on the above analysis, the next section would then try to put forward an array of recommendations for LI-NING'S rebranding path.

\section{STRATEGIES FOR THE RE-BRANDING PATH OF LI-NING}

Based on the problems found in the above analysis, namely 1) Li-NING's sportswear series designs have been outdated. 2) Li-NING does not have enough professional technology to attract customers. 3) LiNING lacks ample marketing efforts for the sportswear series. Five strategies are put forward as below.

Strategy 1: Collaborate with worldwide famous designers and celebrities. It is believed that to improve their design of sportswear series, Li-NING must collaborate with some famous designers and celebrities. As a successful case, Kanye West designed YEEZY for Adidas from 2013 to 2020. The classical design of YEEZY made the brand reputation of Adidas increase more than before. As can be seen from the 2015 Adidas annual report, the CEO of Adidas perceives that those product launches like the Kanye West series helped Adidas Originals to become one of the world's top sneaker brands. Thereby, LI-NING is suggested to find some famous Chinese designers to work with. It is also recommended for LI-NING to collaborate with the designer such as Jackson Wang because they are the celebrities who young people admire.

Strategy 2: Increase investment in research and innovation. This strategy is significant for the long-term development of LI-NING. Especially for its sportswear series, the product technology is one of the most important factors to attract customers. Consequently, LINING should increase investment in the technology of the product. It is also important to collaborate with some scientific institutions and universities to research more useful gear functions for the customers to enhance their competitiveness. After they have their core technology, it is the time when they could conduct the market campaign to gain competitive advantages.

Strategy 3: Comprehensive transformation of the target market to the younger generation. For LI-NING, 
now the main customers are the young generation who like following the fashion trends and pay more attention to the individual needs. They want to express their personalities. The brand should research what those generations are interested in and get the brand's information. To attract that kind of people, LI-NING can perform some activities as follows. Some tactics include constructing the Pop-up shops of sportswear series. A successful case is the fashion series pop-up shop of LI-NING called NING SPACE, held in Beijing in 2018. The sportswear series can also design activities to attract young people to interact with the sports stars. LI-NING can show what innovative technology they developed and its new sportswear series in the shop. They can also show the video on which they sponsor the Chinese sports games so that the younger generation can better understand the brand culture of LI-NING.

Other than that, DIY would also be implicative for LI-NING. As can be seen from the current market offerings, some brands have already provided personalized and customized DIY products such as NIKE, VANS, etc. For example, VANS allows its customers to design the shoes by themselves on the website. More specifically, the customers can choose their favourite all-time style and use the online customization tool to design the product appearance from eyelets, laces to fabric patterns. As for LI-NING, it can give opportunities to allow the young generation to DIY their products. It is also important that LI NING provide similar services to meet the needs of young people.

Strategy 4: Media Channel Enchantment. According to the research data of iResearch in 2018, "Generation $Z^{\prime \prime}$ has been becoming a significant segmentation as online shoppers, which is also deemed the largest proportion of the population with the highest stickability and the strongest channel preference. Since social media, such as the Redbook, Weibo, WeChat, and so forth, has become the main channel for the young generation to obtain the brand's information, LI-NING should pay more attention to these promotional channels. Some more specific suggestions are listed below.

First of all, LI-NING can collaborate with some sports Apps like Keep in China. Keep is a social fitness app that more than 200 million sports lovers use. LINING can sponsor the courses of Keep and let the teachers wear LI-NING's sportswear series products to make collaborations with them. Besides, LI-NING should make more exposure to its sportswear series. LINING can grasp the current sportswear trends to meet the consumer needs of the young people in social media and join in the market of those by sponsoring popular TV shows. It signs the celebrities to be the spokesmen, and establishes online e-commerce channels which only involve sportswear series, such as Taobao. For instance,
LI-NING can attract young people through live and short videos in TikTok or some streaming apps like that. Nowadays, increasing customers tend to buy clothing in the live room because they can clearly see what the products look like as the sellers can demonstrate them. Finally, LI-NING should keep sponsoring the Chinese sports games to extend its public recognition and show its corporate social responsibility.

\section{CONCLUSION}

As a sum of the above analysis, it is found that even though LI-NING has prominent market opportunities, it is simultaneously facing massive challenges, all of which require re-branding practices for LI-NING. Through a number of market analyses, this study provides four strategic recommendations for the optimization of LI-NING's branding. For future studies, it is suggested to test those proposed strategies empirically in the real market environment. Only in this way, a better future for LI-NING can be co-envisaged.

\section{REFERENCES}

[1] Tan, H, \& Xia, W. (2010). Analysis on Marketing Strategy of Li Ning Sports Brand. China Business Review (19), 40-41.

[2] Huang, L. (2014). Thinking Trap of the Development of China's Sporting Goods Industry -Enlightenment from the Brand Dilemma of Li Ning. Physical Education and Science (1), 97-103.

[3] He, Z. (2005). New Thoughts on the Brand Marketing Strategy of "Li Ning". Bulletin of Sports Science and Technology Literature, 13(12), 8-9.

[4] Li, X. (2014). Analysis on the Development Crisis of Li Ning Sports Brand. Sports Culture Guide (03), 119-121.

[5] Zou Y, \& Ouyang, J. (2015). Research on the Development of China's Sporting Goods Industry from the Perspective of Bonus - A Case Study of the Brand Development of Li Ning.

[6] Gao, F. (2006). The repositioning of Li Ning brand. Enterprise Reform and Management (08), 43-44.

[7] Xiang, X, \& Zheng, C. (2020). Research on brand marketing communication of Li Ning in the context of financial media. Stylistic Supplies and Technology, 000(006), 64-65.

[8] Zhao, Y, \& Qiao, L. (2019). Research on Brand Marketing Strategy of Li Ning -- A Case Study of Students in Hangzhou University. Fortune Today (21), 51-52. 